\title{
Maternal transfer of methimazole and effects on thyroid hormone availability in embryonic tissues
}

\author{
Stijn L J Van Herck*, Stijn Geysens*, Edward Bald', Grazyna Chwatko', \\ Evelyne Delezie $^{2}$, Elham Dianati ${ }^{\dagger}$, R G Ahmed ${ }^{\ddagger}$ and Veerle M Darras
}

\author{
Laboratory of Comparative Endocrinology, Department of Biology, KU Leuven, Naamsestraat 61, PB 2464, B-3000 \\ Leuven, Belgium \\ 1Department of Environmental Chemistry, Faculty of Chemistry, University of Lodz, 90-236 Lodz, Poland \\ ${ }^{2}$ Animal Sciences Unit, Institute for Agricultural and Fisheries Research (ILVO), B-9090 Melle, Belgium \\ *(S L J Van Herck and S Geysens contributed equally to this work) \\ ${ }^{\dagger}$ E Dianati is now at Institut National de la Recherche Scientifique, Institut Armand-Frappier, Laval, Quebec, Canada \\ ${ }^{\ddagger} \mathrm{R}$ G Ahmed is now at Division of Anatomy and Embryology, Zoology Department, Beni-Suef University, Beni Suef, \\ Bani Sweif, Bani Sweif Governorate, Egypt
}

Correspondence should be addressed to V M Darras Email veerle.darras@ bio.kuleuven.be

\begin{abstract}
Methimazole (MMI) is an anti-thyroid drug used in the treatment of chronic hyperthyroidism. There is, however, some debate about its use during pregnancy as $\mathrm{MMI}$ is known to cross the mammalian placenta and reach the developing foetus. A similar problem occurs in birds, where $\mathrm{MMI}$ is deposited in the egg and taken up by the developing embryo. To investigate whether maternally derived MMI can have detrimental effects on embryonic development, we treated laying hens with $\mathrm{MMI}$ ( $0.03 \%$ in drinking water) and measured total and reduced MMI contents in the tissues of hens and embryos at different stages of development. In hens, MMI was selectively increased in the thyroid gland, while its levels in the liver and especially brain remained relatively low. Long-term MMI treatment induced a pronounced goitre with a decrease in thyroxine $\left(T_{4}\right)$ content but an increase in thyroidal 3,5,3'-triiodothyronine $\left(T_{3}\right)$ content. This resulted in normal $\mathrm{T}_{3}$ levels in tissues except in the brain. In chicken embryos, MMI levels were similar in the liver and brain. They gradually decreased during development but always remained above those in the corresponding maternal tissues. Contrary to the situation in hens, $T_{4}$ availability was only moderately affected in embryos. Peripheral $T_{3}$ levels were reduced in 14-day-old embryos but normal in 18-day-old embryos, while brain $\mathrm{T}_{3}$ content was decreased at all embryonic stages tested. We conclude that all embryonic tissues are exposed to relatively high doses of MMI and its oxidised metabolites. The effect of maternal MMI treatment on embryonic thyroid hormone availability is most pronounced for brain $\mathrm{T}_{3}$ content, which is reduced throughout the embryonic development period.
\end{abstract}
Key Words
- methimazole
- thyroid hormone
- chicken
- development
- brain

\section{Introduction}

Untreated hyperthyroidism in pregnant women increases the risk for a number of adverse outcomes for the mother and foetus, including intrauterine growth restriction, miscarriage, preterm delivery, pre-eclampsia and congestive heart failure (Luewan et al. 2011). Maternal hyperthyroidism can be treated with anti-thyroid drugs such as http://joe.endocrinology-journals.org DOI: 10.1530/JOE-13-0089
Cㄱ 2013 Society for Endocrinology Printed in Great Britain
Published by Bioscientifica Ltd. 
propylthiouracil (PTU) and methimazole (MMI). However, these drugs may in turn have a negative impact on foetal development as they can cross the placenta. The present clinical guidelines advise to avoid the use of MMI in early pregnancy because it may increase the risk of specific malformations including choanal and oesophageal atresia and aplasia cutis congenita (Wolf et al. 2006, Azizi \& Amouzegar 2011, Rodriguez-Garcia et al. 2011, Vissenberg et al. 2012), but it remains unclear whether these abnormalities are linked to MMI or to the maternal hyperthyroidism itself (Barbero et al. 2008).

While it is known that MMI is transferred from the mother to the embryo/foetus, either through the placenta in mammals or through a deposit in the egg in nonmammalian vertebrates, data on the relative MMI concentrations in different embryonic/foetal tissues are scarce. In addition, to what extent maternal MMI reaching the embryo/foetus is present in the reduced or oxidised form has hardly been investigated. While oxidised MMI metabolites are no longer active as anti-thyroid drugs, they have been associated with cytotoxic effects (Kedderis \& Rickert 1985, Laurence et al. 1998, Heidari et al. 2012) and as such they may still disturb normal development.

It also remains unclear to what extent maternal MMI treatment disturbs thyroid hormone (TH)-dependent development in the embryo/foetus. Maternally derived MMI can block the developing thyroid gland as shown repeatedly in rats (Comer \& Norton 1985, Ruiz de Ona et al. 1988, Calvo et al. 1990). However, the early vertebrate brain is highly dependent on adequate $3,5,3^{\prime}$-triiodothyronine $\left(\mathrm{T}_{3}\right)$ availability, and it may not yet be able to compensate for a reduced TH supply by an increase in type 2 iodothyronine deiodinase (D2) activity as observed in the adult brain (Ruiz de Ona et al. 1988, Van Herck et al. 2012). Apart from inhibiting TH production, it has been found more recently that MMI may also have local anti-thyroid effects in tissues by directly suppressing transcriptional activities mediated by $\mathrm{T}_{3}$ and its receptors (Moriyama et al. 2007).

In this study, we have used the chicken embryo to study the effect of maternal MMI treatment on the developing embryo. It has been shown earlier that MMI is taken up from the egg by the embryo and is capable of disturbing development, including brain development (Iqbal et al. 1987, Liu \& Porter 2004, Kagami \& Nishigori 2010). We measured the levels of MMI and its metabolites in different maternal and embryonic tissues and studied the effect of MMI treatment on thyroxine $\left(\mathrm{T}_{4}\right)$ and $\mathrm{T}_{3}$ availability in these tissues.

\section{Materials and methods}

\section{Animal treatment and tissue sampling}

Experiments were performed on broiler breeder hens (Ross, Belgabroed, Belgium) that were $\sim 30$ weeks old. They were fed a standard diet with iodine content within the advised range for euthyroidism $(1.9 \mathrm{mg} / \mathrm{kg})$. The animals were divided over six pens, with each containing 20 hens and 3 roosters. Those in four pens were treated with $0.03 \%$ 1-methyl-3H-imidazole-2-thione (methimazole, Acros Organics, Geel, Belgium) in the drinking water, while those in two pens served as controls. This dose was based on literature data from studies carried out in rats and chickens aimed at inducing hypothyroidism (Iqbal et al. 1987, Calvo et al. 1990, Rosebrough et al. 2006, Sharlin et al. 2010). The animals were treated for a total of 16 weeks, and we started collecting eggs after 6 weeks of treatment.

Eggs were incubated in a forced draft incubator at $37.5^{\circ} \mathrm{C}$ and $50 \%$ relative humidity and automatically turned at a $45^{\circ}$ angle every hour. The day on which incubation was started was called day 0 (E0). After 6, 14 and 18 days of incubation (E6, E14 and E18), eggs were opened, and the following tissues were sampled: head and trunk at E6; liver, heart, lung, muscle and brain at E14 and E18. Brain was divided into telencephalon, diencephalon, mesencephalon, cerebellum and hindbrain. Tissue samples were immediately frozen in liquid nitrogen and stored at $-80^{\circ} \mathrm{C}$ for later use.

At 10, 14 and 16 weeks of treatment, a number of nonincubated eggs were sampled for MMI measurements. Egg yolk and egg white were separated and stored frozen until MMI analysis.

Treatment was stopped for all animals after 16 weeks, and ten control and ten MMI-treated hens were killed at that moment to collect their liver, kidney and different brain regions.

Prior to tissue sampling, blood samples were collected from hens and from E14 and E18 embryos in heparinised tubes. After centrifugation, plasma was stored at $-20^{\circ} \mathrm{C}$ until analysis.

The Ethical Committee for animal experiments of the KU Leuven approved all the experimental protocols.

\section{Determination of MMI levels}

The method for the determination of reduced and total MMI levels was based on derivatisation with 2-chloro1-methylquinolinium tetrafluoroborate (Bald \& Glowacki 2001) and separation and quantification by ion-pairing

Published by Bioscientifica Ltd. 
reversed-phase liquid chromatography originally developed for human urine (Kusmierek \& Bald 2007). Details of the procedure used for chicken tissues, eggs and embryos have been described elsewhere (G Chwatko, V M Darras \& E Bald, Personal communication 2013).

\section{Determination of $T_{4}$ and $T_{3}$ levels}

$\mathrm{T}_{4}$ and $\mathrm{T}_{3}$ levels in maternal and embryonic tissues were measured following extraction as described previously in detail (Reyns et al. 2002, 2005). Typical recoveries of extracted THs ranged from 55 to $75 \%$ for $\mathrm{T}_{3}$ and from 40 to $60 \%$ for $\mathrm{T}_{4}$. The $\mathrm{T}_{3}$ RIA had a detection limit of $2 \mathrm{fmol}$ and an intra-assay variability of $2.2 \%$. The $\mathrm{T}_{4}$ RIA had a detection limit of $5 \mathrm{fmol}$ and an intra-assay variability of $2.8 \%$. For the $\mathrm{T}_{3} \mathrm{RIA}$, cross-reactivity with $\mathrm{T}_{4}$ was $0.1-0.5 \%$, whereas for the $\mathrm{T}_{4}$ RIA, cross-reactivity with $\mathrm{T}_{3}$ was $3.5 \%$. Hormone levels are expressed as picomole per gram tissue.

$\mathrm{T}_{4}$ and $\mathrm{T}_{3}$ levels in plasma were measured using the same RIA system without extraction, using a standard in hormone-free serum, and results are expressed as picomole per millilitre plasma.

Thyroid glands were homogenised in $500 \mu$ ice-cold barbital buffer (0.05 M, pH 8.6) using a Glass/Teflon Potter tissue grinder system. This step was followed by further ultrasonic homogenisation $(2 \times 25 \mathrm{~s})$. Homogenates were then centrifuged and supernatants were transferred into new tubes. Part of the supernatants was directly frozen and stored at $-20^{\circ} \mathrm{C}$. For enzymatic degradation of thyroglobulin by addition of $150 \mu$ l protease (Sigma P-5147, $6.25 \mathrm{mg}$ protease and $3.13 \mathrm{mg}$ 2-thiouracil in $10 \mathrm{ml}$ Tris- $\mathrm{HCl}$ buffer, $0.75 \mathrm{M}$ and $\mathrm{pH} 8.8$ ) and $15 \mu$ l toluol, $150 \mu \mathrm{l}$ of the supernatants were used. Tubes were stoppered and incubated for 2 days in a shaking water bath at $37^{\circ} \mathrm{C}$.
Finally, tubes were placed in boiling water for $2 \mathrm{~min}$ to inactivate the pronase enzyme, snap frozen and stored at $-20^{\circ} \mathrm{C}$. Dilutions of untreated homogenates (free hormone levels) and enzymatically digested homogenates (total hormone levels) were analysed by RIA, and free and total hormone contents were calculated per thyroid gland.

\section{RT and quantitative PCR}

Total RNA was isolated using TRIzol reagent (Life Technologies) and treated with DNase I (Life Technologies) to remove residual genomic DNA. Total RNA was reversetranscribed using SuperScript III Reverse Transcriptase and Oligo(dT) ${ }_{12-18}$ primers (Life Technologies). Real-time PCR was performed using a thermal cycler, StepOnePlus RealTime PCR Systems (Life Technologies), with Fast SYBR Green Mastermix (Life Technologies) and $300 \mathrm{nM}$ of each primer as listed in Table 1. Non-template and water controls were used to detect non-specific amplification. Each experimental and standard sample was analysed in duplicate. Relative expression values were calculated based on the standard curve with the StepOne Software (Life Technologies) using a 1:5 dilution series of pooled cDNA as the standard. The expression data were analysed using the qBase ${ }^{\text {PLUS }}$ Software (Biogazelle, Zwijnaarde, Belgium). Two reference genes were used for normalisation: glyceraldehyde-3-phosphate dehydrogenase $(G A P D H)$ and cyclophilin for adult hens and GAPDH and $\beta$-actin for embryos.

\section{Deiodinase enzyme assays}

In vitro deiodination activities were determined in microsomes obtained from maternal liver and kidney and in homogenates of the different maternal and embryonic

Table 1 Primer sequences for the quantitative RT-PCR analyses

\begin{tabular}{ll} 
Name & $\begin{array}{l}\text { Accession no. } \\
\text { mRNA }\end{array}$ \\
\cline { 2 - 2 } D2 & NM_204114 \\
D3 & NM_001122648 \\
OATP1C1 & NM_001039097 \\
MCT8 & XM_426274 \\
TSH receptor & NM_001033850; \\
& NM_001193589; \\
NIS & NM_001193588 \\
TTF1 & XM_429095 \\
TPO & NM_204616 \\
TG & AM167549 \\
B-Actin & XM_003640868 \\
GAPDH & NM_205518 \\
Cyclophilin A & NM_204305 \\
& NM_001166326
\end{tabular}

Forward sequence $\left(5^{\prime} \rightarrow 3^{\prime}\right)$

TGT TTC TGA GCC GCT CCA A CAG GAG GAG AAG GTG ATG TAC CA CAT GGG ACG ATA TCA GTA TGA AAG A CAA CTC CTT CGG GAT CAT CTA CA GGT CCT CTG ATA GCT CTG AAC GAT

CAC CAC GGA GGC TGAT GTT GCC GTT CTC CTG TTG CAT CT TTC CGA TAA AGG TAA CAA CCA ATG CAA CGT TTT CCA GGC CAT TG ATG GCT CCG GTA TGT GCA A GAA GCT TAC TGG AAT GGC TTT CC GGC TAC AAG GGC TCC TGC TT

Reverse sequence $\left(5^{\prime} \rightarrow 3^{\prime}\right)$

ACA CTG GAG TTC GGA GCT TCT C

TCT GGA GCC GGG TTT TGT ACT

CGA GAG TGG AGT TTG GCT TTT CT AGC CAA CCC ATG CTG TTT TAA CAC TGC TGT GCT TTC AAG AAC TG

GCG CAG CCA CCG TGA T GAA CAT TTA GCC AGC ATG ATC CA CAG TGC CAC ATG CAG GAG AT CCA GTG ATT GGC CAT GTT TAT G TGT CTT TCT GGC CCA TAC CAA GAT ATC ATC ATA CTT GGC TGG TTT CTC CCG TTG TGG CGC GTA AA

\begin{tabular}{c}
$\begin{array}{c}\text { Amplicon } \\
\text { length (bp) }\end{array}$ \\
\hline 142 \\
100 \\
97 \\
95 \\
119 \\
\\
75 \\
126 \\
87 \\
80 \\
120 \\
97 \\
77
\end{tabular}


brain regions as described in detail earlier (Darras et al. 1992, Reyns et al. 2005). In the D1 activity test, the incubation mixture contained $0.1 \mathrm{mg}$ of protein $/ \mathrm{ml}$ and $1 \mu \mathrm{M} \mathrm{rT} \mathrm{rT}_{3}$ containing 50000 c.p.m. of radiolabelled $\left[{ }^{125} \mathrm{I}\right]-\mathrm{rT}_{3}$, and tubes were incubated at $37^{\circ} \mathrm{C}$ for $30 \mathrm{~min}$. D2 activity was assayed in a similar way by incubating $1 \mathrm{mg}$ of protein/ml and $1 \mathrm{nM} \mathrm{T}$ containing 50000 c.p.m. $\left[{ }^{125} \mathrm{I}\right]-\mathrm{T}_{4}$ at $37^{\circ} \mathrm{C}$ for $120 \mathrm{~min}$. A second mixture was prepared with $100 \mathrm{nM} \mathrm{T}_{4}$ to assess possible interference of D1 activity. Only when iodide production was absent or minimal in the presence of $100 \mathrm{nM} \mathrm{T}_{4}$, enzyme activity using $1 \mathrm{nM} \mathrm{T}_{4}$ was considered to be the true $\mathrm{D} 2$ activity. In the D3 activity test, the incubation mixture contained $1 \mathrm{mg}$ of protein $/ \mathrm{ml}$ and $1 \mathrm{nM} \mathrm{T}_{3}$ containing 150000 c.p.m. $\left[{ }^{125} \mathrm{I}\right]-\mathrm{T}_{3}$ as well as $1 \mu \mathrm{M} \mathrm{rT} \mathrm{T}_{3}$ and $0.1 \mathrm{mM}$ $6 n$-PTU to block possible D1 interference. The mixture was incubated for $120 \mathrm{~min}$ at $37^{\circ} \mathrm{C}$. Activities were calculated as picomol (D1) or femtomol (D2 and D3) of hormone deiodinated per milligram protein and per minute.

\section{Statistical analysis}

All data comparisons between the control group and the MMI group for the given age and tissue were done by Student's unpaired $t$-test. Comparisons with $P$ values $<0.05$ were considered significantly different.

\section{Results}

\section{MMI levels in maternal and embryonic tissues}

We measured MMI levels in the hens, eggs and embryos of the MMI-treated groups to evaluate maternal transfer to the embryos. As not only reduced MMI but also its metabolites may have adverse effects on embryonic development, we used a method allowing discrimination between the total amount of MMI (including oxidised forms) and that of reduced MMI (the anti-thyroid active form). From weeks 10 up to 16 of treatment, the average levels of reduced MMI were $11.0 \pm 0.6 \mu \mathrm{g} / \mathrm{g}$ wet weight for egg yolk ( $76 \%$ of total MMI level) and $12.8 \pm 0.7 \mu \mathrm{g} / \mathrm{g}$ wet weight for egg white ( $95 \%$ of total MMI level; mean \pm s.E.M. for a total of 12 samples). MMI levels in maternal and embryonic tissues are given in Table 2 . As expected, the highest levels were found in the thyroid gland of adult hens. In these animals, reduced MMI levels were also clearly higher in the peripheral tissues (plasma and liver) than in the brain. A different result was found in embryos where reduced MMI levels were similar in the peripheral tissues and brain. E6 embryos had the highest levels and almost all MMI was present in the reduced form. Total MMI concentrations were comparable at E14 and E18, but the percentage present as reduced MMI was clearly lower at E18 than at E14. However, reduced levels in the embryonic brain remained higher than the levels in the adult brain. Owing to the small size of the embryonic thyroid gland, we were not able to determine MMI levels in this tissue.

\section{Effects on maternal thyroid gland activity}

Sixteen weeks of MMI treatment strongly increased the size of the thyroid gland (Table 3). The expression of a number of genes involved in thyroid gland activity was significantly affected, with a decrease in the mRNA levels of thyroid transcription factor 1 (TTF1 (NKX2-1)) and

Table 2 Levels of (MMI*, $\mu \mathrm{g} / \mathrm{g}$ wet tissue weight) in different maternal and embryonic chicken tissues. Embryonic tissues were sampled from eggs collected between weeks 10 and 14 of treatment (eight samples for E6 and three to four samples per tissue for E14 and E18). Samples from hens were collected at the end of the 16-week treatment (ten samples for plasma and three to four samples for tissues). E6, E14 and E18: 6-, 14- and 18-day-old embryos

\begin{tabular}{|c|c|c|c|c|c|c|c|c|}
\hline & \multicolumn{2}{|l|}{ Hen } & \multicolumn{2}{|l|}{ E6 } & \multicolumn{2}{|l|}{ E14 } & \multicolumn{2}{|l|}{ E18 } \\
\hline & Reduced $(\%)^{a}$ & Total & Reduced $(\%)^{a}$ & Total & Reduced $(\%)^{a}$ & Total & Reduced $(\%)^{\mathrm{a}}$ & Total \\
\hline Plasma & $6.6 \pm 0.9^{b}(93 \%)$ & $7.1 \pm 1.0$ & & & & & & \\
\hline Thyroid & $20.9 \pm 2.0(91 \%)$ & $22.8 \pm 2.6$ & & & & & & \\
\hline Head & & & $7.6 \pm 1.2(91 \%)$ & $8.3 \pm 1.4$ & & & & \\
\hline Trunk & & & $7.6 \pm 1.2(97 \%)$ & $7.9 \pm 1.2$ & & & & \\
\hline Liver & $3.5 \pm 1.5(89 \%)$ & $3.9 \pm 0.7$ & & & $3.9 \pm 0.5(83 \%)$ & $4.7 \pm 0.2$ & $2.8 \pm 0.4(77 \%)$ & $3.7 \pm 0.5$ \\
\hline Telencephalon & $2.1 \pm 0.1(92 \%)$ & $2.2 \pm 0.3$ & & & $4.0 \pm 0.6(90 \%)$ & $4.4 \pm 0.6$ & $2.8 \pm 0.4(68 \%)$ & $4.1 \pm 0.5$ \\
\hline Mesencephalon & $1.2 \pm 0.1(56 \%)$ & $2.2 \pm 0.3$ & & & $4.1 \pm 0.4(88 \%)$ & $4.7 \pm 0.6$ & $2.7 \pm 0.3(67 \%)$ & $4.1 \pm 0.5$ \\
\hline Cerebellum & $1.1 \pm 0.1(59 \%)$ & $1.9 \pm 0.1$ & & & $3.7 \pm 0.6(66 \%)$ & $5.6 \pm 0.6$ & $2.7 \pm 0.4(69 \%)$ & $4.0 \pm 0.5$ \\
\hline
\end{tabular}

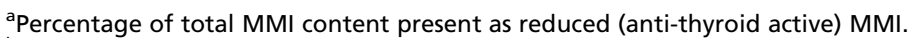

balues represent mean \pm S.E.M.

http://joe.endocrinology-journals.org DOI: 10.1530/JOE-13-0089
(C) 2013 Society for Endocrinology Printed in Great Britain
Published by Bioscientifica Ltd. 
Table 3 Effects of 16 weeks of MMI treatment on maternal thyroid weight $(\mathrm{mg})$ and on total and free thyroid hormone contents (pmol/gland) in adult hens and embryos. Values represent mean \pm s.E.M. for eight to ten samples/group. E14 and E18: 14- and 18-day-old embryos

\begin{tabular}{|c|c|c|c|}
\hline & Control & MMI & $\begin{array}{l}\text { Fold } \\
\text { change }\end{array}$ \\
\hline \multicolumn{4}{|l|}{ Hens } \\
\hline Weight & $190 \pm 18$ & $3299 \pm 454$ & $\times 17^{\dagger}$ \\
\hline Total $\mathrm{T}_{4}$ & $419763 \pm 76320$ & $31984 \pm 5956$ & $\times 0.08^{\dagger}$ \\
\hline Free $\mathrm{T}_{4}$ & $18136 \pm 3178$ & $2048 \pm 450$ & $\times 0.11^{\dagger}$ \\
\hline Total $\mathrm{T}_{3}$ & $952 \pm 99$ & $2175 \pm 349$ & $\times 2.3^{*}$ \\
\hline Free $T_{3}$ & $15.6 \pm 1.9$ & $115 \pm 32$ & $\times 7.4^{*}$ \\
\hline $\begin{array}{l}\text { E14 } \\
\text { Total } \mathrm{T}_{4}\end{array}$ & $164.2 \pm 15.0$ & $18.7 \pm 5.0$ & $\times 0.11^{\dagger}$ \\
\hline Free $\mathrm{T}_{4}$ & $13.81 \pm 1.40$ & $0.48 \pm 0.12$ & $\times 0.03^{\dagger}$ \\
\hline Total $\mathrm{T}_{3}$ & $7.67 \pm 0.64$ & $5.59 \pm 0.85$ & $\times 0.73$ \\
\hline $\begin{array}{l}\text { Free } T_{3} \\
\text { E18 }\end{array}$ & $0.217 \pm 0.55$ & $0.086 \pm 0.021$ & $\times 0.40 *$ \\
\hline Total $\mathrm{T}_{4}$ & $3661 \pm 351$ & $1005 \pm 104$ & $\times 0.27^{\dagger}$ \\
\hline Free $\mathrm{T}_{4}$ & $57.1 \pm 3.6$ & $20.6 \pm 2.6$ & $\times 0.36^{\dagger}$ \\
\hline Total $\mathrm{T}_{3}$ & $21.36 \pm 1.73$ & $13.30 \pm 2.59$ & $\times 0.62 *$ \\
\hline Free $\mathrm{T}_{3}$ & $0.299 \pm 0.043$ & $0.581 \pm 0.095$ & $\times 1.94 *$ \\
\hline
\end{tabular}

${ }^{*} P<0.05$ and ${ }^{\dagger} P<0.001$ compared with the controls (unpaired $t$-test).

thyroglobulin $(T G)$ and a significant increase in the mRNA levels of sodium/iodide symporter (NIS (SLC5A5)), thyroid peroxidase (TPO) and thyrotropin receptor (TSHR) (Fig. 1).

The amount of $\mathrm{T}_{4}$ per weight unit of the thyroid gland was more than 100-fold reduced following MMI treatment, and despite the substantial increase in the size of the thyroid gland, both total and free $\mathrm{T}_{4}$ contents were about tenfold decreased. The amount of $\mathrm{T}_{3}$ per weight unit was far less affected, and in combination with the higher weight of the thyroid gland, this resulted in a twofold increase in total $\mathrm{T}_{3}$ content and a sevenfold increase in free $\mathrm{T}_{3}$ content (Table 3 ).

\section{TH levels in maternal and embryonic tissues}

Blood samples were collected from hens every 2 weeks throughout the treatment period. Circulating $\mathrm{T}_{4}$ levels in the MMI-treated hens showed a steady decrease until 6 weeks of treatment when they stabilised around 50\% of the control levels. Plasma $\mathrm{T}_{3}$ content was mildly decreased at 10 and 14 weeks of treatment, but remained unchanged at all other time points (data not shown).

$\mathrm{T}_{4}$ and $\mathrm{T}_{3}$ levels in maternal tissues are shown in Fig. 2. $\mathrm{T}_{4}$ levels were strongly decreased in the plasma, liver, kidney and different brain regions of the MMI-treated hens, except in the diencephalon. While $\mathrm{T}_{3}$ levels in peripheral plasma, liver and kidney were similar for the control and MMI-treated hens, $\mathrm{T}_{3}$ content was strongly decreased in the telencephalon and mesencephalon and mildly but not significantly decreased in the diencephalon and cerebellum.

The number of eggs produced by the MMI-treated hens decreased and stabilised around week 8 at $20-25 \%$ of the number produced by the control hens. However, the overall quality of the eggs did not change; egg weight, crude energy content, crude protein content and crude lipid content were similar in the MMI-treated and control groups. By contrast, the amount of $\mathrm{T}_{4}$ and $\mathrm{T}_{3}$ deposited in the egg yolk was strongly decreased throughout the egg collection period (Fig. 3). $\mathrm{T}_{4}$ levels in E6 embryos were similar in the trunk and head and were surprisingly not decreased by MMI treatment. At this stage, $T_{3}$ levels were clearly higher in the head than in the trunk and were significantly lower in the head of MMI embryos (Fig. 3).

Maternal MMI treatment decreased circulating $\mathrm{T}_{4}$ levels in E14 and E18 embryos. However, $\mathrm{T}_{4}$ levels in liver, heart, lung, muscle and different brain regions were not altered (Figs 4 and 5). The situation was different for $\mathrm{T}_{3}$. While plasma $\mathrm{T}_{3}$ content was not significantly decreased, levels were, in general, clearly lower in both peripheral tissues and brain in MMI embryos at E14. At $\mathrm{E} 18, \mathrm{~T}_{3}$ levels were still decreased in the brain but no longer in the peripheral tissues (Figs 4 and 5).

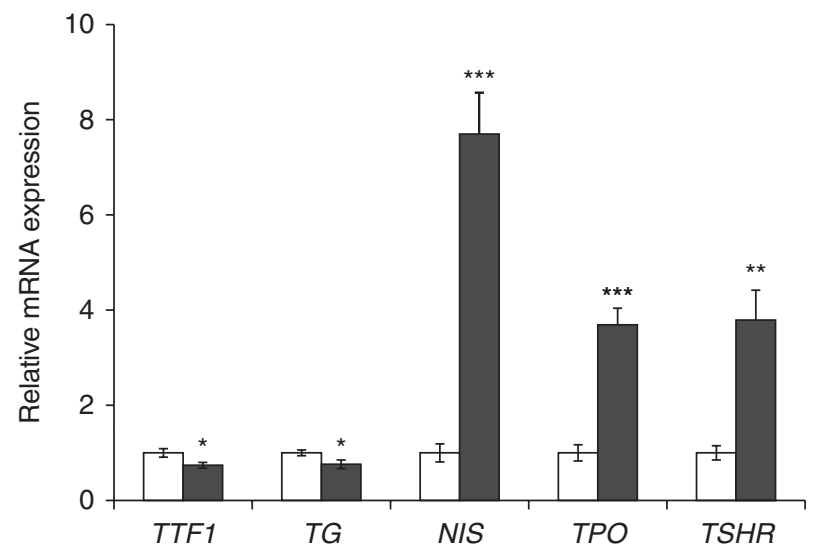

Figure 1

Relative mRNA expression of TTF1, TG, NIS, TPO and TSHR in the thyroid glands of the control (white bars) and MMI-treated (dark bars) hens following 16 weeks of treatment. Expression levels were normalised using GAPDH and cyclophilin as the reference genes. For each gene, levels are expressed relative to the average level in the control group. Values represent mean + S.E.M. for five animals per group. $* P<0.05 * * P<0.01$ and $* * * P<0.001$ (unpaired $t$-test compared with the controls). 

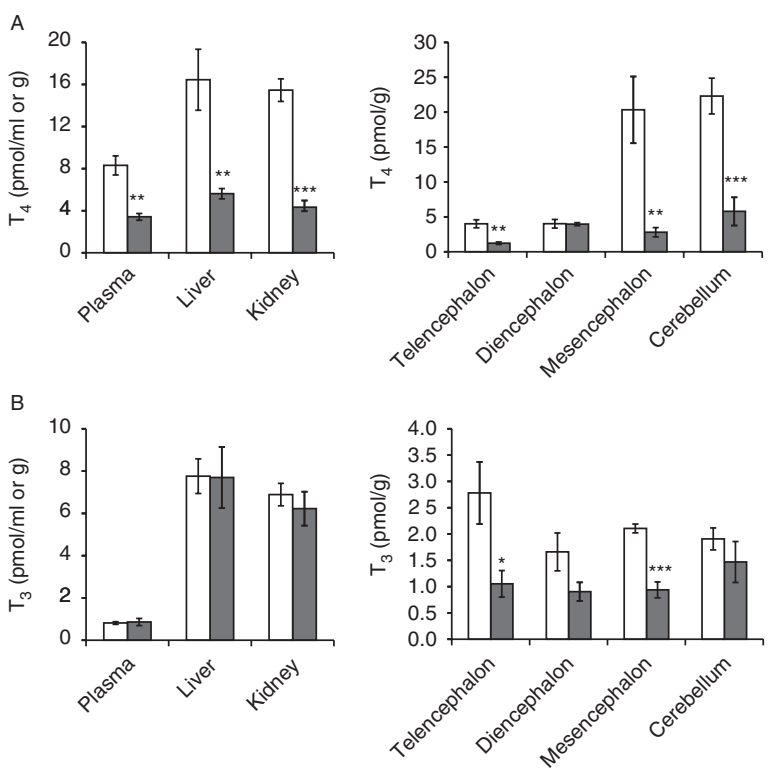

Figure 2

Levels of $T_{4}(A)$ and $T_{3}(B)$ (expressed in picomole per millilitre or gram) in the plasma, liver, kidney and brain of the control (white bards) and MMItreated (dark bars) hens following 16 weeks of treatment. Values represent mean \pm s.E.M. for five animals per group. $* P<0.05, * * P<0.01$ and $* * * P<0.001$ (unpaired $t$-test compared with the controls).

\section{Expression of TH transporters and deiodinases in maternal and embryonic brain}

As MMI treatment clearly affected TH levels in the brain, we measured the mRNA expression of the deiodinases D2 and D3 and the TH transporters OATP1C1 (SLCO1C1) and MCT8 (SLC16A2). Expression was measured in the telencephalon, diencephalon, mesencephalon, cerebellum and hindbrain of the control and MMI-treated hens, but no significant changes were observed. The expression of these four genes was also measured in the telencephalon, diencephalon and mesencephalon of E6 and E14 embryos. No significant changes were found at E6. At E14, the expression of D2 and MCT8 was decreased by respectively 34 and $27 \%(P<0.05)$ but only in the diencephalon.

\section{Deiodinase activity in maternal and embryonic tissues}

MMI treatment did not significantly affect D1 or D3 activity in maternal liver and kidney, but it strongly increased D2 activity in all regions of the maternal brain (Table 4). Moderate but significant increases were also observed in the diencephalon and mesencephalon of E14 embryos. No increases were found in the embryonic brain at E6, where D2 activity was even significantly lower in embryos from MMI eggs compared with the controls (Table 4).
The only significant change in D3 activity was found in the adult brain where activity was decreased in the telencephalon of the MMI-treated hens (0.597 $\pm 0.036 \mathrm{fmol} \mathrm{T}_{3}$ deiodinated $/ \mathrm{mg}$ protein per min vs $0.766 \pm 0.068$ in the controls, $P<0.05)$.

In order to determine whether the presence of MMI as such is able to decrease the efficiency of $\mathrm{T}_{4}$-to- $\mathrm{T}_{3}$ conversion, we also tested D2 activity in the brain homogenates of a number of control embryos in the presence or absence of $20 \mu \mathrm{g} \mathrm{MMI} / \mathrm{ml}$, a concentration corresponding to the highest level observed in tissues (maternal thyroid, $20 \mu \mathrm{g} / \mathrm{g}$ wet weight). The addition of MMI to the homogenates did not alter in vitro D2 activity.

\section{Discussion}

The anti-thyroid drug MMI can be absorbed from the gastrointestinal tract and it accumulates in the thyroid gland where it inhibits TH synthesis by interfering with the action of thyroid peroxidase (Nagasaka \& Hidaka 1976, Vickers et al. 2012). It has been shown in humans and rats that MMI is rapidly metabolised and that a major part is excreted via urine (Skellern \& Steer 1981, Hengstmann \& Hohn 1985, Cooper 2005, Kusmierek \& Bald 2007).
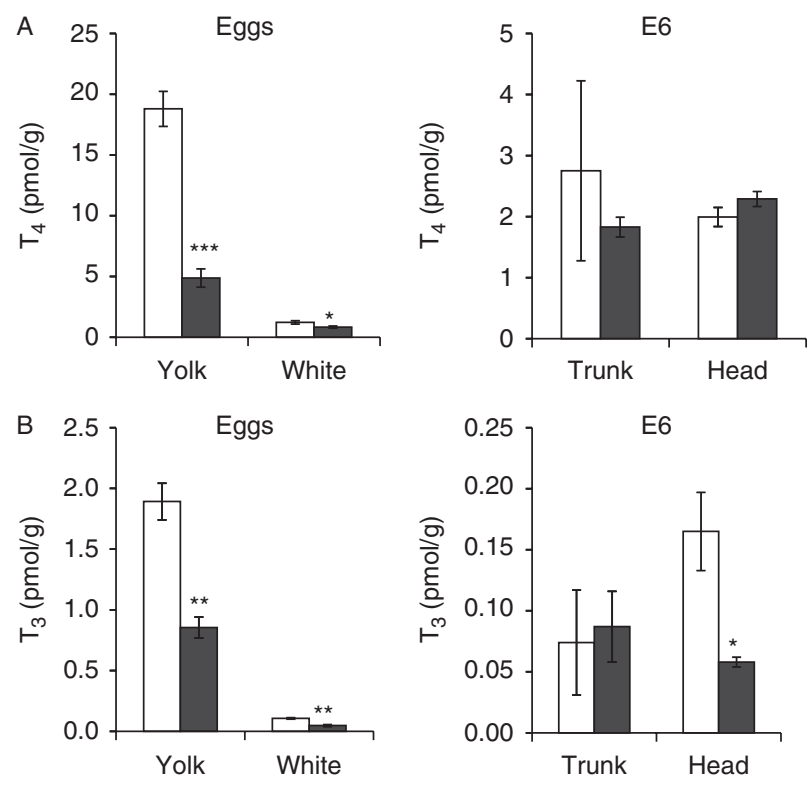

Figure 3

Levels of $T_{4}(A)$ and $T_{3}(B)$ (expressed in picomole per gram) in the eggs and 6-day-old embryos (E6) of the control (white bars) and MMI-treated (dark bars) hens. Eggs were collected following 14 weeks of maternal MMI treatment. Values represent mean \pm s.E.M. for four eggs or embryos per group. ${ }^{*} P<0.05,{ }^{*} P<0.01$ and $* * * P<0.001$ (unpaired $t$-test compared with the controls).

Published by Bioscientifica Ltd 
A

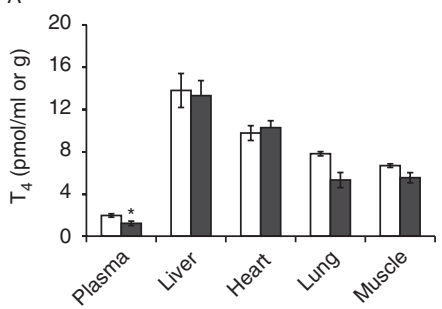

B

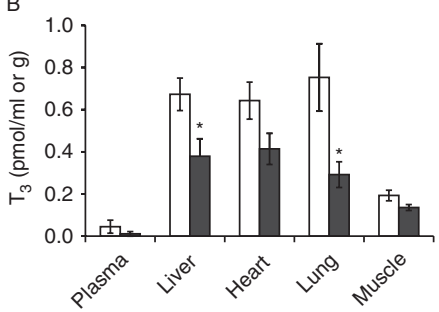

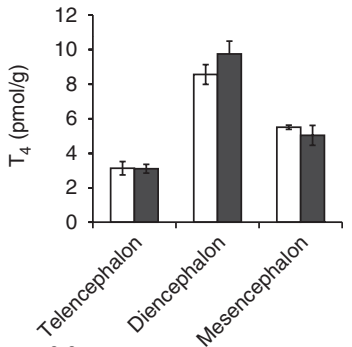

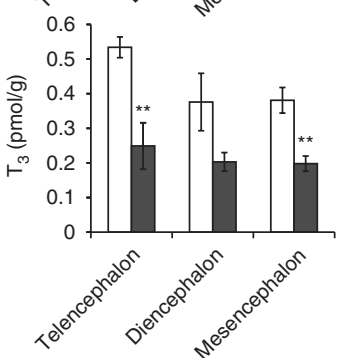

Figure 4

Levels of $T_{4}(A)$ and $T_{3}(B)$ (expressed in picomole per millilitre or gram) in the peripheral tissues and brain of 14-day-old embryos of the control (white bars) and MMI-treated (dark bars) hens. Eggs were collected between weeks 10 and 16 of maternal MMI treatment. Values represent mean \pm S.E.M. for five embryos per group. ${ }^{*} P<0.05$ and ${ }^{*} * P<0.01$ (unpaired $t$-test compared with the controls).

Nevertheless, MMI treatment sometimes induces severe side effects such as agranulocytosis and hepatotoxicity (Cooper 2005, Yang et al. 2012), indicating that a significant amount of MMI and/or its metabolites is present in extra-thyroidal tissues. We measured the levels of reduced MMI and its oxidised metabolites in hens following 16 weeks of treatment. The dose that we used was relatively high compared with the ones used in medical practice. Circulating levels were about fourfold higher than the average levels reported for humans (Mortimer et al. 1997), but relative differences in tissue levels might also apply to humans where tissue data are scarce. As in humans and rats (Marchant \& Alexander 1972, Jansson et al. 1983), MMI specifically accumulated in the thyroid gland. About sixfold lower levels were present in the liver, mainly in the reduced form. Total levels in the brain were about half of those in the liver, suggesting that the adult brain is somehow better protected. Interestingly, we found clear differences in the proportion of MMI present as oxidised metabolites. This was more than $40 \%$ in the mesencephalon and cerebellum, while this was around $10 \%$ in the telencephalon, similar to that observed in the peripheral tissues. So far, it remains unclear whether this difference is the result of a higher local metabolism of MMI or a selective uptake

related to the tissue composition. The fact that total MMI levels are similar could be an element in favour of the first hypothesis.

The major problem with MMI as well as other thionamides in humans and more precisely in pregnant women is that these compounds are transferred to the developing foetus via the placenta and may harm normal development (Cooper 2005, Vissenberg et al. 2012). In birds, essential as well as potentially harmful substances are deposited in the egg and taken up by the embryo during development. Two important conclusions can be drawn from the MMI measurements in chicken embryos. The first one is that although both total and reduced MMI levels in embryonic tissues are gradually decreasing from early towards later stages of development, they always remain above the levels found in the corresponding adult tissues. The second one is that the levels in the embryonic brain are as high as those in the embryonic liver, suggesting that the protective mechanisms possibly present in the adult brain are not yet functional before hatching. Most of the MMI is present in the reduced form, although there seems to be a gradual increase in the percentage of oxidised metabolites, especially in the brain. However, although these metabolites no longer function as anti-thyroid drugs, they can be cytotoxic and
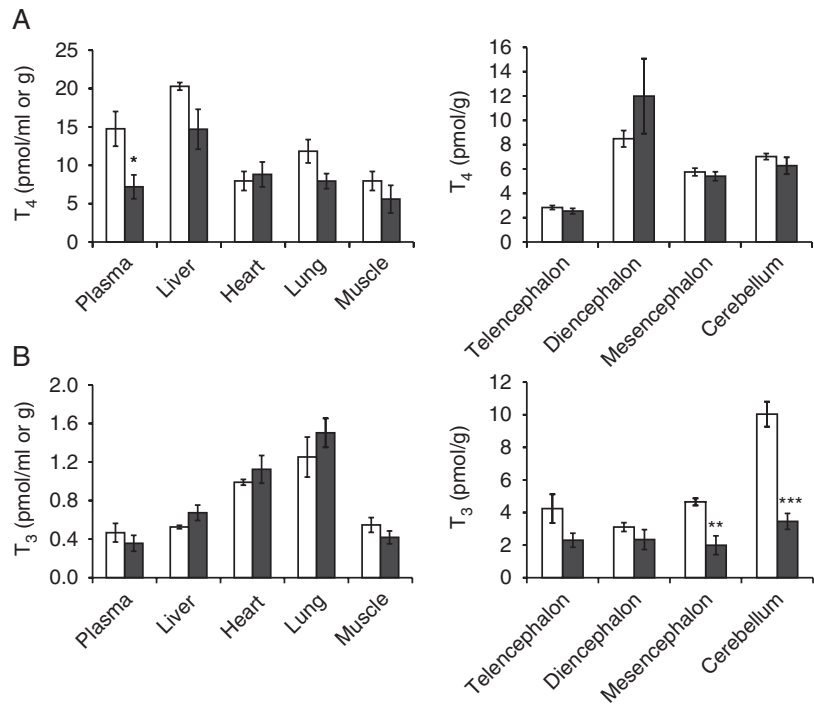

\section{Figure 5}

Levels of $T_{4}(A)$ and $T_{3}(B)$ (expressed in picomole per millilitre or gram) in the peripheral tissues and brain of 18-day-old embryos of the control (white bars) and MMI-treated (dark bars) hens. Eggs were collected between weeks 10 and 16 of maternal MMI treatment. Values represent mean \pm S.E.M. for five embryos per group. ${ }^{\star} P<0.05, * * P<0.01$ and $* * * P<0.001$ (unpaired $t$-test compared with the controls). 
Table 4 Effects of maternal MMI treatment on type 2 deiodinase activity ( $\mathrm{fmol} \mathrm{T}_{4}$ deiodinated/mg protein per min) in maternal and embryonic chicken brain. Values represent mean \pm S.E.M. for four pools/group (E6) or eight individual samples/group (E14 and hens)

\begin{tabular}{l}
\hline \\
\hline Hens \\
Telencephalon \\
Diencephalon \\
Mesencephalon \\
Cerebellum \\
E6 \\
Telencephalon \\
Diencephalon \\
Mesencephalon \\
E14 \\
Telencephalon \\
Diencephalon \\
Mesencephalon \\
Cerebellum
\end{tabular}

\begin{tabular}{c} 
Control \\
\hline \\
$0.499 \pm 0.026$ \\
$0.180 \pm 0.017$ \\
$0.194 \pm 0.018$ \\
$0.311 \pm 0.027$ \\
\\
$0.638 \pm 0.045$ \\
$0.914 \pm 0.068$ \\
$0.693 \pm 0.032$ \\
\\
$4.094 \pm 0.077$ \\
$4.231 \pm 0.090$ \\
$3.477 \pm 0.075$ \\
$3.089 \pm 0.128$
\end{tabular}

MMI

$0.763 \pm 0.057^{\dagger}$

$0.324 \pm 0.016^{\dagger}$

$0.279 \pm 0.010^{\ddagger}$

$0.503 \pm 0.017^{\dagger}$

$0.676 \pm 0.053$

$0.797+0.040$

$0.575 \pm 0.020$ *

$4.600 \pm 0.143 *$

$3.843 \pm 0.115^{*}$

$3.163 \pm 0.167$
$4.343 \pm 0.177$

${ }^{\star} P<0.05,{ }^{\ddagger} P<0.01$ and ${ }^{\dagger} P<0.001$ compared with the controls (unpaired $t$-test).

therefore may still contribute to the adverse effects of MMI on development (Kedderis \& Rickert 1985, Genter 1998).

When investigating maternal thyroid status, we found that the MMI-treated hens were able to keep up normal plasma $\mathrm{T}_{3}$ levels despite a $50 \%$ decrease in circulating $\mathrm{T}_{4}$ levels. The same was true for the TH content in the liver and kidney. One possible mechanism would be an increase in the peripheral conversion of $\mathrm{T}_{4}$ into $\mathrm{T}_{3}$ by outer-ring deiodination and/or a decrease in $\mathrm{T}_{3}$ degradation by innerring deiodination. The results of the in vitro D1 and D3 activity tests in the liver and kidney suggest that this is not the case. By contrast, we observed dramatic changes at the level of the thyroid gland. The most obvious one was the huge goitre, which can most probably be explained by a decrease in the negative feedback of $\mathrm{T}_{4}$ at the level of the pituitary thyrotropes (Huang et al. 2001, Bianco \& Kim 2006). The increased growth of the thyroid gland was accompanied by a highly increased relative expression of the thyrotropin receptor, the sodium/iodide symporter and thyroid peroxidase, while the expression of thyroglobulin and TTF1 was slightly decreased. This is somewhat different from observations in human thyroid cells and rat FRTL-5 cells cultured in vitro where short-term treatment with MMI increased the expression of thyroid peroxidase as well as thyroglobulin (Leer et al. 1991). However, recent studies on human thyroid slices have shown that the effect of MMI on the expression of thyroid-specific genes may vary according to treatment dose and duration (Vickers et al. 2012).
In accordance with the inhibitory effect of MMI on iodine integration into tyrosine, both total and free $\mathrm{T}_{4}$ contents were strongly decreased. By contrast, long-term MMI treatment resulted in a twofold increase in total $\mathrm{T}_{3}$ content and a sevenfold increase in free $\mathrm{T}_{3}$ content. This way the MMI-treated hens could maintain normal $\mathrm{T}_{3}$ levels by shifting from a predominance of $\mathrm{T}_{3}$ produced by peripheral deiodination of $\mathrm{T}_{4}$ to a predominance of $\mathrm{T}_{3}$ produced within the thyroid gland. A similar mechanism has not been found in pregnant rats where MMI treatment reduced $T_{4}$ as well as $T_{3}$ levels in plasma, liver and heart, although the relative decrease was smaller for $\mathrm{T}_{3}$ (Calvo et al. 1990). This could be a species-related difference, but it is also possible that the treatment period of 7 days in the rat experiment was too short to induce substantial changes in the ratio of $\mathrm{T}_{3}: \mathrm{T}_{4}$ content and release of the thyroid gland.

The adaptive mechanism in adult hens seems to be sufficient to maintain $T_{3}$ levels in peripheral tissues such as liver and kidney, but not in the brain, which is known to depend heavily on $\mathrm{T}_{4}$ uptake and local $\mathrm{T}_{4}$-to- $\mathrm{T}_{3}$ conversion by D2 (Silva \& Matthews 1984, Grijota-Martinez et al. 2011). Despite a clear increase in D2 activity, most brain regions did not succeed in compensating for the reduced supply of $\mathrm{T}_{4}$ and showed low $\mathrm{T}_{3}$ levels. This finding illustrates once more that the thyroid status of a specific tissue cannot be simply deduced from the TH levels present in circulation.

A tissue-specific control also seems to be active at the level of the ovary, since both $\mathrm{T}_{4}$ and $\mathrm{T}_{3}$ concentrations in the eggs were severely reduced despite the normal plasma $\mathrm{T}_{3}$ levels. This control occurred independently of the overall protein and lipid contents of the eggs, which were not changed by MMI treatment. The fact that the total number of eggs was reduced confirmed earlier data on the inhibitory effect of hypothyroidism on female reproduction in a number of species including fish, amphibians and humans (Van der Geyten et al. 2001, Krassas et al. 2010, Carr \& Patino 2011).

Maternal MMI treatment clearly has an effect on tissue TH availability in developing embryos but, surprisingly, predominantly on $T_{3}$. Again, this is not reflected in the circulation since both E14 and E18 embryos from MMI eggs showed significantly reduced plasma $\mathrm{T}_{4}$ levels, while plasma $\mathrm{T}_{3}$ content was not significantly different. At $\mathrm{E} 6, \mathrm{~T}_{4}$ levels in the body of the control and MMI embryos were similar. As at that stage the embryonic thyroid gland is developing but not yet functional, this suggests that the embryo can compensate for the reduced $\mathrm{T}_{4}$ content in the egg yolk by a more efficient $T_{4}$ uptake. The embryonic thyroid gland normally starts contributing to $\mathrm{TH}$

Published by Bioscientifica Ltd. 
availability in the embryo during the second week of incubation and the effects observed at E14 and E18 should therefore be interpreted as the combined result of the reduced $\mathrm{TH}$ content in the yolk and the inhibition of embryonic thyroid gland activity by MMI taken up by the embryo.

As in adult hens, the brain of E14 and E18 embryos from MMI eggs had clearly lower $\mathrm{T}_{3}$ levels but without a decrease in $\mathrm{T}_{4}$ content, a combination that is difficult to explain. The possibility of a direct inhibitory effect of MMI on D2 activity in brain homogenates was tested, but it proved to be negative. In vitro D2 activity tests on the brain of E14 embryos showed that the amount of active enzyme was higher in the diencephalon and mesencephalon of MMI embryos compared with the controls, indicative of a compensatory response. This response was, however, not present in all brain regions, and it was less pronounced than the strong response in the brain of adult hens. Together with the fact that there was no compensatory increase in D2 activity in the brain at E6, this confirms earlier observations that the typical compensatory response of deiodinases to altered $\mathrm{TH}$ availability is not yet mature in young embryos/foetuses (Ruiz de Ona et al. 1988, Gereben et al. 2008, Sharlin et al. 2010, Van Herck et al. 2012). The single changes found in D2 and MCT8 mRNA in different brain regions of E14 embryos are also not in line with a compensatory response at the level of gene expression and rather point to a delay in the normal ontogenetic expression pattern of these genes in hypothyroid MMI embryos (Geysens et al. 2012, Van Herck et al. 2012). The fact that hypothyroidism as such did not change the mRNA expression of the deiodinases in the embryonic as well as adult brain is in agreement with literature data from embryonic and post-hatch quail exposed to perchlorate (Chen et al. 2008, 2009).

One more interesting observation is that $T_{3}$ availability was reduced not only in the brain but also in the peripheral tissues of E14 embryos, while this was no longer the case at E18. During the second half of embryonic development, the relative contribution of the embryonic thyroid gland to total $\mathrm{TH}$ availability increases over time and is therefore higher at E18 where the hypothalamopituitary-thyroid axis is almost completely mature. As in adult hens, the embryonic thyroid gland may have increased its relative release of $T_{3}$ and this is in line with the fact that at E18 free $T_{3}$ content was increased in the thyroid gland of MMI embryos. The slower maturation of the thyroid axis in rodents compared with chickens may also help to explain why in rat foetuses from MMI-treated dams both $T_{4}$ and $T_{3}$ contents are decreased in the peripheral tissues and brain, similar to the situation in the dams themselves (Calvo et al. 1990).

Taken together, our data show that long-term MMI treatment of hens severely reduces $T_{4}$ production in the thyroid gland but induces a relative increase in thyroidal $\mathrm{T}_{3}$ content. As a result, peripheral tissues can maintain normal $\mathrm{T}_{3}$ levels, but the brain is clearly hypothyroid. As in mammals, the treatment leads to the maternal transfer of MMI and its oxidised metabolites to the developing embryo. Levels in embryonic tissues are relatively high, especially at the early stages, and MMI and/or its oxidised metabolites may therefore have cytotoxic effects on all developing tissues including the brain. Long-term MMI treatment also reduces $\mathrm{TH}$ availability in the egg yolk, resulting in lower $\mathrm{T}_{3}$ availability in the early embryonic brain. At later stages, the maternally derived MMI also disturbs embryonic thyroid gland function. Combined with the lower TH content of the yolk, this results in a reduced $\mathrm{T}_{3}$ content in the peripheral tissues and brain of 14-day-old embryos and in the brain of 18-day-old embryos. We can conclude that the maternal transfer of MMI and its metabolites to the embryo can be harmful for embryonic development, in particular, for the brain, by a combination of anti-thyroidal and possibly local cytotoxic effects, an observation that may also be of relevance to the human situation.

\section{Declaration of interest}

The authors declare that there is no conflict of interest that could be perceived as prejudicing the impartiality of the research reported.

\section{Funding}

This work was supported by grants from the KU Leuven University (OT/07/036 and OT/11/041) and the Fund for Scientific Research-Flanders (G.0455.08 and G.0307.12).

\section{Author contribution statement}

S L J V and S G were responsible for setting up of the experiment, collection of all samples, analysis of gene expression and statistical analysis of all data. $\mathrm{E} B$ and $\mathrm{G} C$ performed the $\mathrm{MMI}$ measurements. E D was responsible for the daily supervision of the MMI treatment of the hens and the collection and quality control of the eggs. E D and R G A assisted in the analysis of embryonic brain samples. V M D supervised the thyroid hormone extractions and deiodination tests and prepared the manuscript.

\section{Acknowledgements}

The authors thank Lut Noterdaeme, Lieve Geenen, Willy Van Ham, David Demedts, André Vermeulen and Jos De Deken for their valuable technical support.

Published by Bioscientifica Ltd. 


\section{References}

Azizi F \& Amouzegar A 2011 Management of hyperthyroidism during pregnancy and lactation. European Journal of Endocrinology 164 871-876. (doi:10.1530/EJE-10-1030)

Bald E \& Glowacki R 2001 2-Chloro-1-methylquinolinium tetrafluoroborate as an effective and thiol specific UV-tagging reagent for liquid chromatography. Journal of Liquid Chromatography \& Related Technologies 24 1323-1339. (doi:10.1081/JLC-100103450)

Barbero P, Valdez R, Rodriguez H, Tiscornia C, Mansilla E, Allons A, Coll S \& Liascovich R 2008 Choanal atresia associated with maternal hyperthyroidism treated with methimazole: a case-control study. American Journal of Medical Genetics. Part A 146A 2390-2395. (doi:10.1002/ajmg.a.32497)

Bianco AC \& Kim BW 2006 Deiodinases: implications of the local control of thyroid hormone action. Journal of Clinical Investigation 116 2571-2579. (doi:10.1172/JCI29812)

Calvo R, Obregon MJ, Ruiz de Ona C, Escobar del Rey F \& Morreale de Escobar G 1990 Congenital hypothyroidism, as studied in rats. Crucial role of maternal thyroxine but not of 3,5,3'-triiodothyronine in the protection of the fetal brain. Journal of Clinical Investigation 86 889-899. (doi:10.1172/JCI114790)

Carr JA \& Patino R 2011 The hypothalamus-pituitary-thyroid axis in teleosts and amphibians: endocrine disruption and its consequences to natural populations. General and Comparative Endocrinology 170 299-312. (doi:10.1016/j.ygcen.2010.06.001)

Chen Y, Sible JC \& McNabb FM 2008 Effects of maternal exposure to ammonium perchlorate on thyroid function and the expression of thyroid-responsive genes in Japanese quail embryos. General and Comparative Endocrinology 159 196-207. (doi:10.1016/j.ygcen.2008. 08.014)

Chen Y, McNabb FM \& Sible JC 2009 Perchlorate exposure induces hypothyroidism and affects thyroid-responsive genes in liver but not brain of quail chicks. Archives of Environmental Contamination and Toxicology 57 598-607. (doi:10.1007/s00244-009-9304-0)

Comer CP \& Norton S 1985 Early development in the caudate and thyroid of methimazole-treated rats. Neurotoxicology 6 25-35.

Cooper DS 2005 Antithyroid drugs. New England Journal of Medicine 352 905-917. (doi:10.1056/NEJMra042972)

Darras VM, Visser TJ, Berghman LR \& Kuhn ER 1992 Ontogeny of type I and type III deiodinase activities in embryonic and posthatch chicks: relationship with changes in plasma triiodothyronine and growth hormone levels. Comparative Biochemistry and Physiology. A, Comparative Physiology 103 131-136. (doi:10.1016/0300-9629(92)90252-L)

Genter MB 1998 Evaluation of olfactory and auditory system effects of the antihyperthyroid drug carbimazole in the Long-Evans rat. Journal of Biochemical and Molecular Toxicology 12 305-314. (doi:10.1002/ (SICI) 1099-0461(1998) 12:5 < 305::AID-JBT7 > 3.0.CO;2-P)

Gereben B, Zeold A, Dentice M, Salvatore D \& Bianco AC 2008 Activation and inactivation of thyroid hormone by deiodinases: local action with general consequences. Cellular and Molecular Life Sciences 65 570-590. (doi:10.1007/s00018-007-7396-0)

Geysens S, Ferran JL, Van Herck SL, Tylzanowski P, Puelles L \& Darras VM 2012 Dynamic mRNA distribution pattern of thyroid hormone transporters and deiodinases during early embryonic chicken brain development. Neuroscience 221 69-85. (doi:10.1016/j.neuroscience. 2012.06.057)

Grijota-Martinez C, Diez D, Morreale de Escobar G, Bernal J \& Morte B 2011 Lack of action of exogenously administered $\mathrm{T}_{3}$ on the fetal rat brain despite expression of the monocarboxylate transporter 8. Endocrinology 152 1713-1721. (doi:10.1210/en.2010-1014)

Heidari R, Babaei H \& Eghbal M 2012 Mechanisms of methimazole cytotoxicity in isolated rat hepatocytes. Drug and Chemical Toxicology. In press. (doi:10.3109/01480545.2012.749272)
Hengstmann JH \& Hohn H 1985 Pharmacokinetics of methimazole in humans. Klinische Wochenschrift 63 1212-1217. (doi:10.1007/ BF01733780)

Huang H, Cai L, Remo BF \& Brown DD 2001 Timing of metamorphosis and the onset of the negative feedback loop between the thyroid gland and the pituitary is controlled by type II iodothyronine deiodinase in Xenopus laevis. PNAS 98 7348-7353. (doi:10.1073/pnas.131198998)

Iqbal A, Decuypere E, Kuhn ER, Schneider R, Verheyen G \& Huybrechts LM 1987 The influence of methimazole on the thyrotrophic and peripheral activity of thyrotrophin and thyrotrophin-releasing hormone in the chick embryo and growing chicken. Domestic Animal Endocrinology 4 291-298. (doi:10.1016/0739-7240(87)90025-7)

Jansson R, Dahlberg PA, Johansson H \& Lindstrom B 1983 Intrathyroidal concentrations of methimazole in patients with Graves' disease. Journal of Clinical Endocrinology and Metabolism 57 129-132. (doi:10.1210/jcem-57-1-129)

Kagami K \& Nishigori H 2010 Effects of prenatal exposure to antithyroid drugs on imprinting behavior in chicks. Physiology \& Behavior 101 297-301. (doi:10.1016/j.physbeh.2010.05.015)

Kedderis GL \& Rickert DE 1985 Loss of rat liver microsomal cytochrome P-450 during methimazole metabolism. Role of flavin-containing monooxygenase. Drug Metabolism and Disposition 13 58-61.

Krassas GE, Poppe K \& Glinoer D 2010 Thyroid function and human reproductive health. Endocrine Reviews 31 702-755. (doi:10.1210/er. 2009-0041)

Kusmierek K \& Bald E 2007 Determination of methimazole in urine by liquid chromatography. Talanta 71 2121-2125. (doi:10.1016/j.talanta. 2006.08.019)

Laurence C, El Ghomari MJ, Le Questel JY, Berthelot M \& Mokhlisse R 1998 Structure and molecular interactions of anti-thyroid drugs. Part 3. Methimazole: a diiodine sponge. Journal of the Chemical Society. Perkin Transactions 2 1545-1551. (doi:10.1039/A803002b)

Leer LM, Cammenga M, van der Vorm ER \& de Vijlder JJ 1991 Methimazole increases thyroid-specific mRNA concentration in human thyroid cells and FRTL-5 cells. Molecular and Cellular Endocrinology 78 221-228. (doi:10.1016/0303-7207(91)90126-D)

Liu L \& Porter TE 2004 Endogenous thyroid hormones modulate pituitary somatotroph differentiation during chicken embryonic development. Journal of Endocrinology 180 45-53. (doi:10.1677/joe.0.1800045)

Luewan S, Chakkabut P \& Tongsong T 2011 Outcomes of pregnancy complicated with hyperthyroidism: a cohort study. Archives of Gynecology and Obstetrics 283 243-247. (doi:10.1007/s00404-0101362-z)

Marchant B \& Alexander WD 1972 The thyroid accumulation, oxidation and metabolic fate of 35 S-methimazole in the rat. Endocrinology 91 747-756. (doi:10.1210/endo-91-3-747)

Moriyama K, Tagami T, Usui T, Naruse M, Nambu T, Hataya Y, Kanamoto N, Li YS, Yasoda A, Arai H et al. 2007 Antithyroid drugs inhibit thyroid hormone receptor-mediated transcription. Journal of Clinical Endocrinology and Metabolism 92 1066-1072. (doi:10.1210/jc.2006-1621)

Mortimer RH, Cannell GR, Addison RS, Johnson LP, Roberts MS \& Bernus I 1997 Methimazole and propylthiouracil equally cross the perfused human term placental lobule. Journal of Clinical Endocrinology and Metabolism 82 3099-3102. (doi:10.1210/jc.82.9.3099)

Nagasaka A \& Hidaka H 1976 Effect of antithyroid agents 6-propyl-2thiouracil and 1-methyl-2-mercaptoimidazole on human thyroid iodine peroxidase. Journal of Clinical Endocrinology and Metabolism $\mathbf{4 3}$ 152-158. (doi:10.1210/jcem-43-1-152)

Reyns GE, Janssens KA, Buyse J, Kuhn ER \& Darras VM 2002 Changes in thyroid hormone levels in chicken liver during fasting and refeeding. Comparative Biochemistry and Physiology. Part B, Biochemistry \& Molecular Biology 132 239-245. (doi:10.1016/S1096-4959(01)00528-0)

Reyns GE, Verhoelst CH, Kuhn ER, Darras VM \& Van der Geyten S 2005 Regulation of thyroid hormone availability in liver and brain by glucocorticoids. General and Comparative Endocrinology 140 101-108. (doi:10.1016/j.ygcen.2004.10.006) 
Rodriguez-Garcia C, Gonzalez-Hernandez S, Hernandez-Martin A, Perez-Robayna N, Sanchez R \& Torrelo A 2011 Aplasia cutis congenita and other anomalies associated with methimazole exposure during pregnancy. Pediatric Dermatology 28 743-745. (doi:10.1111/j.15251470.2011.01572.x)

Rosebrough RW, Russell BA \& McMurtry JP 2006 Studies on doses of methimazole (MMI) and its administration regimen on broiler metabolism. Comparative Biochemistry and Physiology. Part A, Molecular \& Integrative Physiology 143 35-41. (doi:10.1016/j.cbpa.2005.10.019)

Ruiz de Ona C, Obregon MJ, Escobar del Rey F \& Morreale de Escobar G 1988 Developmental changes in rat brain $5^{\prime}$-deiodinase and thyroid hormones during the fetal period: the effects of fetal hypothyroidism and maternal thyroid hormones. Pediatric Research 24 588-594. (doi:10.1203/00006450-198811000-00010)

Sharlin DS, Gilbert ME, Taylor MA, Ferguson DC \& Zoeller RT 2010 The nature of the compensatory response to low thyroid hormone in the developing brain. Journal of Neuroendocrinology 22 153-165. (doi:10.1111/j.1365-2826.2009.01947.x)

Silva JE \& Matthews PS 1984 Production rates and turnover of triiodothyronine in rat-developing cerebral cortex and cerebellum. Responses to hypothyroidism. Journal of Clinical Investigation $\mathbf{7 4}$ 1035-1049. (doi:10.1172/JCI111471)

Skellern GG \& Steer S 1981 The metabolism of [2-14C]methimazole in the rat. Xenobiotica 11 627-634. (doi:10.3109/00498258109045874)
Van der Geyten S, Toguyeni A, Baroiller JF, Fauconneau B, Fostier A, Sanders JP, Visser TJ, Kuhn ER \& Darras VM 2001 Hypothyroidism induces type I iodothyronine deiodinase expression in tilapia liver General and Comparative Endocrinology 124 333-342. (doi:10.1006/gcen. 2001.7722)

Van Herck SL, Geysens S, Delbaere J, Tylzanowski P \& Darras VM 2012 Expression profile and thyroid hormone responsiveness of transporters and deiodinases in early embryonic chicken brain development. Molecular and Cellular Endocrinology 349 289-297. (doi:10.1016/j.mce. 2011.11.012)

Vickers AE, Heale J, Sinclair JR, Morris S, Rowe JM \& Fisher RL 2012 Thyroid organotypic rat and human cultures used to investigate drug effects on thyroid function, hormone synthesis and release pathways. Toxicology and Applied Pharmacology 260 81-88. (doi:10.1016/j.taap. 2012.01.029)

Vissenberg R, van den Boogaard E, van Wely M, van der Post JA, Fliers E, Bisschop PH \& Goddijn M 2012 Treatment of thyroid disorders before conception and in early pregnancy: a systematic review. Human Reproduction Update 18 360-373. (doi:10.1093/humupd/dms007)

Wolf D, Foulds N \& Daya H 2006 Antenatal carbimazole and choanal atresia: a new embryopathy. Archives of Otolaryngology - Head \& Neck Surgery 132 1009-1011. (doi:10.1001/archotol.132.9.1009)

Yang J, Zhong J, Zhou LZ, Hong T, Xiao XH \& Wen GB 2012 Sudden onset agranulocytosis and hepatotoxicity after taking methimazole. Internal Medicine 51 2189-2192. (doi:10.2169/internalmedicine.51.7845)

Received in final form 18 April 2013

Accepted 22 April 2013

Accepted Preprint published online 22 April 2013
(C) 2013 Society for Endocrinology Printed in Great Britain 